\title{
La aplicación judicial del derecho en el Proyecto de Código Procesal Civil
}

\author{
Iván Hunter Ampuero*
}

\begin{abstract}
RESUMEN
En el presente trabajo se aborda la problemática del poder del juez para aplicar el derecho en el marco del Proyecto de Código Procesal Civil. El autor, junto con exponer las tesis que tradicionalmente han explicado esta potestad, intenta justificar que un juez con el poder de utilizar ampliamente los materiales jurídicos cumple con la función de tutela de los derechos de los ciudadanos que consiste en dar la razón a quien prueba ser titular de un derecho vulnerado más que al que alega correctamente una norma jurídica. Para esta finalidad analiza los casos y el momento procesalmente adecuado para debatir la nueva calificación propuesta por el juez.
\end{abstract}

Aplicación judicial del derecho - iura novit curia - derecho de defensa

\section{The judicial application of law in the Civil Procedural Act Project}

\begin{abstract}
The present paper tackles the judge's power issue in order to apply the law relating to the Civil Procedural Code project. The author, in addition to expose the different theories that traditionally have explained this authority, tries to justify that the judge's power to widely use the legal materials accomplishes the tutelage of the civil rights. This tutelage function is based on giving the reason to the party that proves to be subject of the violated right more than to the one that correctly alleges legal regulations. Hence, the author analyzes different cases and the suitable procedural moment to debate the new qualification suggested by the judge.
\end{abstract}

Judicial application of the law - iura novit curia - right of defense

* Abogado, Magíster y Doctor en Derecho, Profesor de Derecho Procesal de la Universidad Austral de Chile, Valdivia, Chile. Ivanhunter@uach.cl

Este trabajo fue realizado en el marco y con el financiamiento del Proyecto Fondecyt $\mathrm{N}^{\circ} 11110185$, titulado "Iura novit curia. La aplicación judicial del Derecho en el Proyecto de Código Procesal Civil", del cual el autor de este trabajo es su investigador responsable.

Artículo recibido el 30 de marzo de 2012 y aceptado para su publicación por el Comité Editorial el 31 de mayo de 2012. 


\section{INTRODUCCIÓN}

$\mathrm{L}$ a reforma al proceso penal, sin duda la más exitosa de nuestro sistema procesal, tuvo la gran virtud de generar consensos en las funciones que debían asumir los intervinientes. En el proceso civil, en cambio, la definición teórica de cuáles son las tareas procesales que deben asumir las partes y el juez aún tiene a la doctrina en franca disputa. Tradicionalmente se le atribuye a las partes la carga de introducir los hechos y la prueba, mientras que al juez determinar el Derecho aplicable a la controversia. El Proyecto de Código Procesal Civil (en adelante PCPC ${ }^{1}$ ) contiene una frondosa y sistemática regulación de la prueba y la forma de cómo deben introducirse los hechos. Sin embargo, guarda un completo silencio respecto al otro extremo de un litigio: los materiales jurídicos o normativos que resuelven la contienda, al no existir disposición que sirva para explicar el alcance del poder del juez en el ámbito de la utilización de los materiales jurídicos.

Es frecuente para los que utilizan diariamente el proceso civil como herramienta de trabajo enfrentarse a situaciones en que la pretensión de un ciudadano encuentre plena acogida en el ordenamiento jurídico, pero bajo argumentaciones o materiales jurídicos muy diferentes a los consignados en la demanda. Ante esta situación se podría adoptar alguno de los siguientes caminos: o el juez se aparta de la calificación jurídica propuesta en la demanda y la acoge en base a una calificación diversa y autónoma; o bien, la rechaza justificando que los materiales o argumentos jurídicos están incorrectamente invocados.

Ambas opciones presentan dificultades. Si se autoriza al juez a resolver la controversia con total prescindencia a la discusión o argumentos planteados por las partes, podría infringir el derecho de defensa en su vertiente de la contradicción. El derecho del ciudadano de participar en contradicción en la formación del contenido material de la sentencia sería vulnerado al permitir que el juez justifique su decisión en elementos normativos ignorados por las partes.

La segunda dificultad puede surgir si se estima que el cambio en la calificación jurídica de la pretensión implica violar el principio dispositivo, al modificarse el criterio de relevancia con que el ciudadano incorpora al proceso un determinado hecho. El que afirma ser titular de un derecho o interés alega jurisdiccionalmente ciertos hechos como base de su pretensión, y que constituyen el presupuesto de la norma aplicable para conceder el beneficio solicitado. Esa alegación según parte de la doctrina forma parte del principio dispositivo. En consecuencia, si el juez acoge la demanda incorporando en la sentencia otros hechos distintos a los que forman esa alegación, entonces hay una modificación en el criterio de relevancia y, en consecuencia, una posible vulneración del principio dispositivo.

${ }^{1}$ Para estos consideré necesario trabajar con el Proyecto de ley enviado por el Ejecutivo el 12 de marzo de 2012. Desde la perspectiva académica, este proyecto es el resultado del trabajo conjunto entre el Ejecutivo y las Universidades nacionales, por tal motivo puede considerarse que constituye un articulado más elaborado y reflexionado que los anteriores proyectos. 
Por otro lado, desechar una pretensión cuando el ingrediente jurídico ha sido mal invocado no parece una solución eficiente desde la utilización racional del proceso, ni tampoco representativa de una tutela judicial efectiva. El Estado sufre un desgaste económico importante cuando el proceso finaliza con una sentencia absolutoria que se funda únicamente en la impericia de un ciudadano -exactamente de su abogado- al momento de seleccionar el marco normativo adecuado a su relación jurídica. Tampoco parece ajustarse a una tutela judicial efectiva y a los fines del proceso civil negar la protección jurisdiccional de un derecho o interés por no haber sido correctamente invocada la norma o institución de la cual se deriva la petición del ciudadano, aun cuando el juez constate su existencia y lesión.

Bajo este contexto: ¿qué libertad se le debe reconocer al juez al momento de aplicar el Derecho al caso sometido a su decisión? ¿Es libre el juez para acoger una demanda bajo una calificación jurídica diversa a la propuesta por el actor? De aceptarse positivamente esa primera interrogante surge otra igual de relevante: ¿Cuál es el momento adecuado para que el juez pueda recalificar las posiciones jurídicas sustentadas por el demandante?

Este trabajo intentará justificar dos hipótesis en relación al problema planteado. La primera es la necesidad de reconocer al juez un amplio campo en la utilización de los materiales jurídicos que estime pertinentes para la correcta decisión de litigio, libertad que está sometida a dos límites como son el respeto por la petición concreta y la contradicción previa entre los litigantes. La segunda hipótesis sostiene que el momento adecuado para discutir y recalificar -si es necesario- los extremos jurídicos de la controversia es la audiencia preliminar, puesto que en ese momento se determina la carga de probar los hechos que constituyen el presupuesto fáctico de las normas invocadas.

Para esta finalidad comenzaré (I) por averiguar si las concepciones del proceso civil sirven para justificar un poder amplio del juez. Luego (II) expondré uno de los más recurridos argumentos para justificar la distribución de tareas procesales; posteriormente (III) daré cuenta de las explicaciones que la doctrina suele recoger para explicar el poder del juez en la utilización del Derecho. En el (IV) expondré algunas claves para sugerir la incorporación de una regla que permita ensanchar el ámbito de actuación del juez en la utilización del Derecho. Luego (V) definiré la necesidad de entender a la contradicción como un mecanismo legitimador de la posibilidad del juez en la aplicación del Derecho. Finalizaré (VI) proponiendo y justificando un modelo de aplicación judicial del Derecho en el marco del PCPC, y con las (VII) conclusiones.

\section{LA APLICACIÓN JUDICIAL DEL DERECHO Y LOS FINES DEL PROCESO CIVIL}

La pregunta respecto a cómo y en qué medida influyen los fines del proceso civil y de la jurisdicción en el poder del juez para utilizar los materiales jurídicos no debe contestarse de una forma puramente descriptiva. Es cierto que la investigación acerca de los fines del proceso suele presentarse con una apariencia descriptiva con la finalidad de comprender las normas que sustentan a un determinado sistema procesal. Entender 
la lógica interna del proceso es una herramienta a la que puede recurrir el operador al momento de interpretar y aplicar la norma procesal.

Al contrario, me parece que la forma correcta de plantear el tema es formulando o planteando fines cuya consecución a través del proceso se estima relevante. Esta segunda mirada se dedica a la tarea de definir cómo la norma debería ser para alcanzar esos fines propuestos, y corresponde a un discurso del tipo político procesal del cual pueden desprenderse buenas razones para preferir una u otra herramienta. Así, nos colocamos en el ámbito de las propuestas de políticas públicas para el diseño procesal.

Con todo, hay que observar que los fines del proceso civil resultan vitales para definir, en el contexto de una reforma, los poderes de los jueces, y en especial, el ámbito de libertad para la aplicación del Derecho. Sin embargo, tampoco resulta adecuado plantear el asunto en términos dicotómicos; más bien la consecución de algunos fines tenderá a robustecer los poderes de los jueces, al tiempo de aumentar las posibilidades de control para las partes. Al contrario, la opción por otros fines puede limitar considerablemente las potestades de los jueces sin llegar a desaparecer. Se trata, por tanto, de un asunto de grado o extensión de los poderes, más que de su reconocimiento o eliminación.

Esta reflexión, sin embargo, no se ha realizado con la profundidad que merece, al menos en la literatura nacional que ha escrito sobre la reforma ${ }^{2}$. La doctrina comparada que se ha preocupado de esta temática ha sostenido, con algunos matices, la existencia de dos grandes fines del proceso civil. Se trata de fines no del todo incompatibles, pero que postulan epicentros diversos de la actividad jurisdiccional.

La primera aproximación es la que entiende que el proceso civil tiene como única finalidad resolver conflictos jurídicamente relevantes, asumiendo una función eminentemente pragmática en la medida que se destina a lograr la paz social mediante la extirpación del conflicto ${ }^{3}$. En este aspecto, el proceso se orientaría básicamente a la obtención de la certeza jurídica por medio de la cosa juzgada; la decisión no requiere ninguna condición especial, más allá de las estrictamente procesales (requisitos formales y plazo de dictación). Desde luego que la calidad y justicia de la decisión no son relevantes para que el proceso cumpla su función, y se trataría de valores agregados de segundo orden, cuya obtención no es necesaria para legitimarla. Por ello, la decisión ilegal como aquella que se asienta en bases fácticas no reales son eficaces y cumplen con la misión a que se destina el proceso ${ }^{4}$. La certeza y seguridad jurídica que se alcanza con la decisión judicial tiene un carácter exclusivamente formal, esto es, goza de independencia respecto

\footnotetext{
2 Puede verse, dentro de las excepciones: Bordalí, A., "Justicia del proceso y de la sentencia civil", en $L a$ reforma Procesal Civil en Chile, Cuadernos de Extensión Jurídica 16, Universidad de los Andes, Santiago, 2009, pp. 95 y 96; Hunter, I., "Rol y poderes del juez civil: una mirada desde la eficiencia del proceso" en Revista de Derecho Universidad Católica del Norte, año 18, N², 2011, pp. 76 a 83, y; Marinoni, L., Pérez Ragone, A., y Núñez, R., Fundamentos del proceso civil. Hacia una teoría de la adjudicación, Abeledo Perrot, Legalpublishing, Santiago, 2010, pp. 119 y ss.

${ }^{3}$ Vid., por todos: Moreno, V. y Cortés, V., Introducción al Derecho Procesal, Tirant lo Blanch, Valencia, 2004 , p. 46.

${ }^{4}$ Taruffo, M., Páginas sobre la justicia civil, Marcial Pons, Madrid, 2009, p. 247.
} 
a su acierto 5 . El Estado debe únicamente asegurar a los ciudadanos el desarrollo de un procedimiento justo, con prescindencia de lo que se resuelva.

Esta concepción está unida a dos dogmas que condicionan la posición y rol del juez en el proceso civil ${ }^{6}$. El primero es la necesidad de proteger su imparcialidad. La dotación de poderes a los jueces, en cualquiera de los ámbitos, es sometida al test de la imparcialidad, ya que se entiende que cualquier actividad que pueda efectuar el órgano con influencia en la decisión significa arriesgarla. El legislador, por tanto, debe reducir al mínimo la intervención del órgano jurisdiccional. Lo anterior resulta de toda lógica si el proceso se mira únicamente como un procedimiento para solventar contiendas.

El segundo dogma apunta a la naturaleza privada del objeto del proceso civil. El proceso es parangonado al mercado, por lo que debe funcionar como un sistema autosuficiente capaz de satisfacer de la manera más adecuada los intereses privados libremente contrapuestos, sin necesidad de que el Estado intervenga. Para ello resulta esencial fomentar el libre juego de los litigantes que desde sus homólogas posibilidades de acciones y defensas lo llevan a un resultado óptimo, similar al que brinda el juego de la oferta y la demanda. La intervención del Estado por medio del juez generaría una distorsión en la satisfacción de los intereses particulares ${ }^{7}$.

Estas características permitieron a un sector doctrinal negar la posibilidad de que el juez tenga los instrumentos procesales para evitar que por un error en la calificación jurídica o por defectos en la invocación de la fundamentación jurídica se desechen pretensiones que, bajo diversos fundamentos, encuentran plena acogida en el ordenamiento ${ }^{8}$. Estos instrumentos son propios de los procedimientos en que la disputa recae sobre bienes jurídicos indisponibles o donde se encuentra comprometido el interés público o general. Es el caso, por ejemplo, del proceso penal o constitucional en que se generan reglas destinadas a facilitar la tarea del juez. Pero cuando la disputa versa sobre bienes esencialmente disponibles la decisión es adoptada en relación a lo que las partes, desde sus parciales perspectivas, indican al juez, no siendo necesario buscar ni la norma ni la institución adecuada para los fines de la justicia9 9 .

${ }^{5}$ Cortés, V., "La eficacia del proceso de declaración", en Constitución, Derecho y Proceso, Estudios en memoria de los profesores Vicente Herche Quemada y Ángel Duque Barragues. Zaragoza, Facultad de Derecho Universidad de Zaragoza, 1983, p. 387.

${ }^{6}$ Díaz, J., Principios de aportación de parte y acusatorio: la imparcialidad del juez, Editorial Comares, Granada, 1996, p. 417.

${ }^{7}$ Díaz Cabiale, con certera precisión explica que "así al igual que el mercado se justifica como un sistema autosuficiente para satisfacer de la manera más adecuada los intereses privados, sin necesidad de intervención estatal, el proceso resulta ser el lugar idóneo para que el juego de las partes, al presentar el aspecto de la realidad más favorable a sus intereses, permita alcanzar el resultado más justo sin necesidad de que el órgano jurisdiccional indague o practique actividad probatoria". Ibid., p. 418.

${ }^{8}$ Vid., Damián, J., "La fase de alegaciones", en Hacia una nueva justicia civil, Fundación El Monte, Sevilla, 1998, p. 67.

${ }^{9}$ Ibidem. 
Esto ya lo advertía Damaska ${ }^{10}$ cuando indicaba que mientras más apoyo encuentre el tribunal en las razones jurídicas sustentadas por las partes para definir la cuestión controvertida, ese proceso se acercará en mayor grado a un ideal de resolución de conflictos. El juez decide dentro de los límites jurídicos estipulados por las partes, importando exclusivamente la resolución de controversias ${ }^{11}$.

Frente a esta tesis, se instala la que entiende que el proceso es un mecanismo de tutela y garantía de los derechos subjetivos e intereses legítimos mediante la actuación del orden jurídico. El Estado no saca nada con reconocer al ciudadano la titularidad de un derecho si no lo garantiza jurisdiccionalmente. La protección de un derecho adquiere la misma relevancia que su reconocimiento, con lo que resulta esencial que el proceso civil deba orientarse a obtener decisiones justas basadas en la verdad; esta sería la única forma de tutelar efectivamente los derechos de los ciudadanos ${ }^{12}$. En esta perspectiva el punto central es la correlación indisoluble entre el reconocimiento de un derecho o un interés jurídicamente protegido y la posibilidad de su tutela en el proceso a través de una adecuada gama de medios de actuación o de realización jurisdiccional ${ }^{13}$.

Esta última tesis no invoca razones de absoluta necesidad en orden a justificar el poder del juez para buscar la norma aplicable al caso apartándose del esquema jurídico propuesto por los litigantes ${ }^{14}$, pero su finalidad parece no admitir discusión en tal sentido. La posibilidad de desmarcarse de los fundamentos jurídicos de la pretensión y acogerla en base a uno diverso presta mayor eficacia al reconocimiento de los derechos ejercitados en el proceso ${ }^{15}$.

Recogiendo esta última concepción como finalidad del proceso civil, hay dos cuestiones que resultan esenciales para justificar un poder amplio de los jueces para utilizar los materiales normativos: en primer lugar que la actividad jurisdiccional es eminentemente pública, desarrollada por los órganos del Estado radicados en el Poder Judicial. Por eso es evidente que tienda a satisfacer fines públicos propios de un Estado Democrático de Derecho. En segundo lugar, la jurisdicción es una garantía secundaria que busca proteger o restablecer la legalidad frente a actos que vulneran los derechos de los ciudadanos. En

${ }^{10}$ Cfr., Damaska, M., Las caras de la justicia y del poder del Estado. Análisis comparado del proceso legal, Editorial Jurídica de Chile, Santiago, 2000, pp. 197 a 200.

${ }^{11}$ En cierta forma este modelo es propio de los sistemas del common law en que "la función principal del juez, incluso en los contenciosos diferentes de los derecho privado clásico, es resolver litigios concretos entre particulares. Las funciones de decir el derecho, de interpretarlo de manera coherente o de regular la sociedad acudiendo a normas generales, no son más que incidentes". Garapon, A. y Papadopoulos, I., Juzgar en Estados Unidos y en Francia. Cultura jurídica francesa y common law, Editorial Legis, Bogotá, 2008, p. 228.

12 Taruffo, M., Páginas sobre la justicia civil, op. cit., p. 22, y Comoglio, L., "I modeli di garanzia costituzionale del proceso", en Rivista Trimestrale di Diritto e Procedura Civile, año XLV, No 3, 1991, p. 675.

${ }^{13}$ Comoglio, L., "I modeli di garanzia costituzionale del proceso", op. cit., p. 675.

${ }^{14}$ Esta afirmación es sin perjuicio de lo que indica Damaska en el sentido de que la aplicación de la máxima da mibi factum, dabo tibi ius (denme los hechos y yo, el juez, les daré el derecho) parece más cercana a un proceso destinado a implementar políticas estatales, cuestión que permite justificar que el tribunal pueda sentenciar un caso conforme a una teoría jurídica no planteada por las partes. Cfr., Damaska, M., op. cit., p. 201.

${ }^{15}$ Cfr. Ormazábal, G., Iura novit curia. La vinculación del juez a la calificación jurídica de la demanda, Marcial Pons, Madrid, 2007, p. 119. 
este sentido, resulta antitético postular que la jurisdicción y el proceso civil tienen por finalidad otorgar protección a los derechos de los ciudadanos frente actos que vulneran la ley y, al mismo tiempo, entender que esa protección se brinda en la medida que los ciudadanos acierten con la invocación del Derecho.

En definitiva, si se asume que el proceso civil es un instrumento de protección y tutela de los derechos de los ciudadanos podrá comprenderse que no es posible dejar entregada completamente a las partes la tarea de escoger, alegar e invocar de modo correcto el Derecho del caso concreto. La tutela efectiva de un derecho -en la medida que se pruebe su existencia y vulneración- no puede ser descargada exclusivamente en los litigantes, en la medida de que otorgar protección de un derecho e interés es una finalidad que asume el Estado como garantía para los ciudadanos. Esto significa que el juez deberá cumplir un rol relevante en la calificación jurídica de la pretensión, así como también suplir o complementar los argumentos jurídicos esgrimidos por las partes. Si la obtención de la tutela de un derecho subjetivo e interés depende, en gran parte, de los materiales jurídicos que se empleen para derivar la petición concreta, resulta sensato que el Estado asuma un papel importante cuando las partes han fracasado en esa tarea.

Una tesis contraria a la expuesta haría depender la efectividad de la tutela jurisdiccional a la experticia de la parte (o más específicamente de su abogado) y no en la actuación del Derecho. Por ende, constatados los supuestos fácticos de una norma jurídica que autoriza los efectos pretendidos por el actor, corresponderá al juez aplicarla con plena autonomía a si esa norma fue invocada como fundamento de la demanda o si la fundamentación jurídica permite sustentar la calificación jurídica propuesta.

\section{El JUEZ AL DERECHO Y LOS LITIGANTES A LOS HECHOS}

Uno de los argumentos más afianzados para entender que el juez goza de una amplia libertad en la selección de los materiales jurídicos es su aparente cercanía con el Derecho, mientras que los litigantes con los hechos y la prueba. Se trata de una fórmula sencilla que ha sido el argumento más aceptado para distribuir los roles entre partes y juez en el proceso civil. Paradójicamente los textos legales chilenos, al menos los que regulan el procedimiento civil, contienen una regulación extensa y frondosa de los hechos y la prueba, pero nada dicen respecto de los materiales normativos, e incluso dan a entender, en una primera lectura, que esa tarea le corresponde a las partes (Art. 253 $\mathrm{N}^{\circ} 4$ PCPC). Esta aproximación, no obstante, es solo aparente. Aun sin norma expresa la jurisprudencia ha sido unánime en entender que les corresponde un rol activo en la aplicación del Derecho, planteando una rigurosa separación entre cuestiones fácticas y cuestiones jurídicas ${ }^{16}$.

${ }^{16}$ Desde muy temprano que nuestros tribunales de justicia fueron afirmando en sus fallos que les correspondía asumir un papel amplio en la utilización de las normas jurídicas. Así, la Corte Suprema, en sentencia de 6 de mayo de 1964, indica: "en materia civil los jueces tienen únicamente iniciativa en la aplicación de la ley; y las partes de allegar los hechos en que se basan las acciones y excepciones deducidas. Los jueces de derecho, entonces, 
No obstante, me parece que para comprender cabalmente el ámbito de libertad de los jueces en la aplicación del Derecho no es suficiente recurrir a un expediente técnico. Precisa una explicación mucho más compleja y, desde luego, más emparentada a nuestras concepciones acerca del proceso y la jurisdicción.

En este sentido, ningún sistema normativo puede funcionar sin hacer un acto de fe en algunos dogmas que, si bien son de difícil realización práctica, nadie se atrevería a discutirlos; en efecto, cuando los ciudadanos no cumplen espontáneamente las normas jurídicas y se produce la lesión al interés jurídicamente tutelado por la norma, el Estado, previa excitación del titular de ese interés, reacciona recomponiendo la legalidad quebrantada. Esta actividad es desarrollada por los jueces a través de un proceso guiado por los principios de igualdad y contradicción. Para que este orden pueda cumplir su función de motivar las conductas de los ciudadanos es fundamental entender, o más bien creer, que los jueces conocen íntegramente el derecho objetivo, único -al menos en apariencia y teoría- que puede legitimar y justificar la protección de un derecho e interés por sobre otro.

En esto consiste, precisamente, el postulado de que los jueces y tribunales conocen tanto la existencia de las normas que deben resolver la controversia como el contenido de éstas. Esta circunstancia eximiría a las partes de la labor de alegar y probar los elementos jurídicos de una pretensión, junto con liberar al juez de las alegaciones jurídicas que las partes aducen para fundamentarlas ${ }^{17}$. En cierta forma, la reafirmación del derecho como sistema normativo se logra suponiendo que existen órganos estatales capaces de dominar íntegramente la malla normativa y brindar una solución adecuada a una controversia sobre derechos. De esta forma, el dogma de que los tribunales conocen la legalidad funciona también como una suerte de garantía de que el ciudadano logrará el pleno disfrute de sus derechos no dependiendo de la experticia en la alegación de los datos jurídicos, sino que en la razón de su interés. Además es un complemento esencial del postulado del legislador racional, puesto que la garantía última de racionalidad y justicia del ordenamiento descansa en los jueces cuando aplican la ley. En otras palabras, son los jueces los encargados de dar operatividad a la racionalidad que se predica del ordenamiento cuando resuelven sus disputas sobre derechos ${ }^{18}$.

tienen el deber inexcusable de aplicar a los hechos invocados y probados los preceptos legales pertinentes, aun cuando no los aduzcan las partes”. En el mismo sentido: C. Suprema, 6 de mayo de 1964, R.D.J., t. 61, sec. $1^{\text {a }}$, p. 81. En similar sentido: C. Suprema, 25 de julio de 1958, R.D.J., t. 55, sec. 1a , p. 188; C. Concepción, 29 de abril de 1963, R.D.J., t. 60, sec. $2^{\text {a }}$, p. 49; C. Corte, 25 de noviembre de 1963, R.D.J., t. 60, sec. $1^{\text {a }}$, p. 356; C. Suprema, 11 de agosto de 1965, R.D.J., t. 62, sec. $1^{\text {a }}$, p. 272; C. Suprema, 7 de junio de 1972, R.D.J., t. 69, sec. $1^{\text {a }}$, p. 75 . En otra sentencia de la C. Suprema, de 11 de agosto de 1965 , R.D.J., t. 62, sec. $1^{\text {a }}$, p. 272, se elevó esta distribución de tareas procesales al carácter de "axioma jurídico, que como tal no requiere demostración". Para un análisis crítico de nuestra jurisprudencia: Hunter, I., "Iura novit curia en la jurisprudencia civil chilena" en Revista de Derecho de la Universidad Austral de Chile, Vol. XXIII, No 2, 2010, pp. 212 a 214.

${ }^{17}$ Vid., Ezquiaga, F., Iura novit curia y aplicación judicial del derecho, Editorial Lex Nova, Valladolid, 2008, p. 18.

${ }^{18}$ Como explica Ezquiaga, haciendo referencia a la importancia capital de esta máxima en el funcionamiento del sistema jurídico, se trataría de una "elaboración de la ciencia jurídica que sistematiza el ordenamiento jurídico, 
Por otro lado, si se analizan las garantías orgánicas y procesales que el Estado reconoce al ciudadano puede comprenderse que están encaminadas a asegurar la imparcialidad e independencia de los jueces como forma de permitir su estricta sujeción a la ley. Por eso, es hasta cierto punto contradictorio asumir que la organización jurisdiccional y las garantías de los ciudadanos están encaminadas a repeler las causas que puedan llevar a los jueces a no seguir adecuadamente lo que dice la ley y negar indebidamente la protección de un derecho o interés y, al mismo tiempo, entender que la tarea de tutelar derechos e intereses queda supeditada a la correcta invocación que se haga de la ley.

Es la presunción de conocimiento del Derecho por parte de los jueces -en cuanto dogma que permite el funcionamiento del sistema jurídico- la que condiciona y determina la distribución de roles, asumiendo el juez la tarea de aportar los materiales normativos por tener una evidente proximidad a ellos. En consecuencia, la tarea de las partes sería simplemente la de aportar los materiales fácticos y la prueba. En estos aspectos, son las partes las que están en una situación de proximidad, pudiendo cumplir de manera más eficiente esas tareas. Los ciudadanos no tendrían ningún tipo de función en la determinación de los elementos normativos de la litis, y será el juez quien decida cuáles son las reglas jurídicas que amparan o desestiman la petición de tutela del justiciable.

\section{EXPLICACIÓN TRADICIONAL AL PODER DEL JUEZ PARA}

\section{APLICAR EL DERECHO}

La doctrina nacional en específico ${ }^{19}$ y la comparada en general no han orquestado una respuesta satisfactoria al problema de la vinculación del juez al Derecho alegado por el actor. En el Derecho comparado, esencialmente en España e Italia, han sido escasas las obras que han abordado este problema de manera sistemática ${ }^{20}$, aun cuando prácticamente todos los manuales de Derecho Procesal hacen referencia a la máxima iura novit curia. Es más, ni siquiera existe un consenso terminológico en la doctrina, desde que los conceptos "fundamento jurídico" "fundamentación jurídica”, "razonamiento jurídico" o "calificación jurídica”, son utilizados en diversos sentidos. Sin embargo, es un lugar común observar que la literatura suele enfrentar este problema recurriendo a dos expedientes: en primer lugar, a través del objeto del proceso, por medio de las teorías de la substanciación e individualización; y en segundo lugar, haciendo referencia a los elementos que componen la causa de pedir.

articula las funciones legislativa y jurisdiccional y se configura como un armazón o estructura que sostiene toda la organización jurídica”. Ibídem.

${ }^{19}$ Para Chile puede verse: Hunter, I., "Iura novit curia en la jurisprudencia civil chilena”, op. cit., pp. 197 a 221, y Romero, A., La cosa juzgada en el proceso civil. Doctrina y jurisprudencia, Editorial Jurídica de Chile, Santiago, 2002, pp. 72 y 73.

${ }^{20}$ Ormazábal, G., op. cit., passim, claramente es una excepción, al efectuar un estudio completo y sistemático de la máxima iura novit curia en el derecho español y comparado. 


\section{Teoria de la sustanciación e individualización}

Las teorías de la sustanciación e individualización nacen en Alemania a principios del siglo XX como una forma de definir el objeto del proceso ${ }^{21}$; no obstante, también han sido utilizadas, especialmente en España, para explicar el ámbito de libertad del juez en la utilización de los materiales jurídicos ${ }^{22}$. Se trata de teorías no completamente antagónicas pero que colocan el acento en elementos distintos.

Para la teoría de la individualización lo primordial en la identificación del objeto del proceso es la concreta relación jurídica que se hace valer en juicio ${ }^{23}$. Aquí, por tanto, el demandante debe correlacionar los hechos o realidades empíricas en que funda la demanda en concretas normas jurídicas que permiten obtener el resultado pretendido ${ }^{24}$. Como se podrá fácilmente apreciar para esta teoría no es suficiente la pura invocación de los hechos, es necesario, además, calificarlos jurídicamente. Para que exista relación jurídica (derecho subjetivo, título jurídico, etc.) el actor debe calificar esos hechos a la luz de las normas sustantivas, de manera que cualquier modificación en el Derecho aplicable cambia el objeto del proceso. De esta forma, el tribunal no puede intervenir en los elementos jurídicos proponiendo una calificación jurídica diversa a la esgrimida por el actor, y deberá sujetarse estrictamente a la que fundamenta la demanda; de lo contrario, estaría modificando la relación jurídica hecha valer en juicio, proponiendo el juzgamiento sobre una diversa. Consecuencia de esta tesis es que no existe cosa juzgada ni litispendencia cuando un nuevo juicio versa sobre idéntico hechos pero bajo una calificación jurídica diversa.

Por su lado, la teoría de la sustanciación implica centrar el objeto del proceso no sobre el derecho o la relación jurídica, sino sobre el hecho puesto como fundamento, o más exactamente, sobre el derecho delimitado por el hecho constitutivo ${ }^{25}$. A diferencia de la anterior teoría, la sustanciación coloca el énfasis en el conjunto de bechos afirmados por el actor como fundamento de su pretensión, de manera que el juez queda

${ }^{21}$ Identificar el objeto del proceso no es un esfuerzo puramente doctrinal, ya que tiene importantes consecuencias en varias instituciones del proceso civil. Por eso, estas tesis tratan de identificar qué elementos de una pretensión pueden modificarse sin alterar su objeto (modificación de la demanda), o bien qué elementos pueden considerarse idénticos entre un proceso y otro para que opere la cosa juzgada o la litispendencia. De ahí que el ámbito de libertad del juez para aplicar el derecho tenga repercusiones no solo en la decisión final sino en otros ámbitos del proceso.

${ }^{22}$ Vid., por todos: Gimeno, V., Derecho procesal civil. I. El proceso de declaración. Parte general. Segunda edición, 2007, Colex, Madrid, 2007, pp. 211 y ss.

${ }^{23}$ Ricci, G., “'Individuazione' o 'sostanziazione’ nella reforma del proceso civile”, en Rivista Trimestrale de Diritto e Procedura Civile, año XLIX, 1995, p. 1229. También puede verse: Nasi, A., Disposizione del diritto e azione dispositiva, Contributio allo Studio del principio dispositivo nel processo civile di cognizione, Giuffrè Editore, Milán, 1965, p. 89. De la Oliva, A., Objeto del proceso y cosa juzgada en el proceso civil, Thomson Civitas, Madrid, 2005, p. 52, explica que por "relación jurídica" hay que entender el título jurídico esgrimido, esto es, el derecho subjetivo, negocio jurídico, etc., que se afirma en la pretensión.

${ }^{24}$ Cfr., Gimeno, V., op. cit., p. 211.

${ }^{25}$ Vid., Ricci, G., op. cit., pp. 1232 y 1233; Nasi, A, op. cit., p. 92, y De la Oliva, A., op. cit., p. 52. 
amarrado a éstos pero no a la calificación que se le haya dado ${ }^{26}$. Aun cuando esta tesis no está destinada a explicar la distribución de tareas procesales, de su sola formulación resulta evidente: las partes asumen el imperativo de alegar los hechos constitutivos de la pretensión (o si se quiere, carga de la alegación), y el juez la de traducir esos hechos y subsumirlos en las normas del ordenamiento que permitan conceder el efecto jurídico (derecho subjetivo) deseado por el demandante. Con esto queda claro que la potestad del juez en la aplicación del Derecho es sumamente amplia, al tener que investigar y aplicar la norma jurídica que estime pertinente. De igual forma, toda modificación en los aspectos jurídicos de la pretensión no importa un cambio en el objeto del proceso. Consecuencia de esta tesis es que existe cosa juzgada y litispendencia cuando un nuevo juicio versa sobre idénticos hechos pero bajo una calificación jurídica diversa.

\section{Teoría de la causa de pedir}

Otra de las teorías más difundidas para explicar el poder del juez en la utilización de las normas jurídicas es la que define los elementos que conforman la causa de pedir. Esta tesis no es más que una repetición de la anterior, pero encuentra más sentido en la práctica nacional desde que sirve para definir los supuestos de la cosa juzgada y la litispendencia. Por ende, goza de mayor aceptación a nivel de la doctrina y jurisprudencia nacional.

Existe aceptación en torno a que la "causa de pedir" es "aquella situación de hecho jurídicamente relevante y susceptible, por tanto, de recibir la tutela jurídica solicitada" 27. O en términos del actual Art. 177 del Código de Procedimiento Civil (en adelante CPC), "el fundamento inmediato del derecho deducido en juicio". El problema consiste en determinar qué se entiende por "situación de hecho jurídicamente relevante". Al respecto se ha dicho que existen dos tesis acerca de la delimitación de la causa de pedir $^{28}$ : la primera entiende que la causa de pedir está conformada tanto por los hechos como por los fundamentos jurídicos que califican esos hechos. De esta forma un cambio en los elementos normativos de la pretensión significa modificar la causa de pedir, no pudiendo el juez, por tal motivo, utilizar argumentos o fundamentos jurídicos distintos a los esgrimidos por el actor. Desde este punto de vista no hay cosa juzgada cuando el nuevo juicio versa sobre idénticos datos fácticos pero difiere en los elementos jurídicos.

Frente a esta postura, se encuentra la que entiende que la causa de pedir está conformada por los puros hechos expuestos en la demanda, de manera que es perfectamente posible modificar los materiales jurídicos. La consecuencia inmediata de esta tesis es que el juez tiene un amplio poder para utilizar el Derecho, no pudiendo considerarse que falla ultra petita si se aparta de los fundamentos esgrimidos por las partes.

26 Gimeno, V., op. cit., p. 211.

27 Tapia, I., El objeto del proceso. Alegaciones. Sentencia. Cosa juzgada, Editorial La Ley, Madrid, 2000, p. 21.

${ }^{28}$ Sigo a Romero, A., "La congruencia de la sentencia", en Revista Chilena de Derecho, Vol. XXV, No 2 , 1998, p. 448, y Ortells, M., Derecho Procesal Civil, Thomson Aranzadi, 2008, p. 260. 
Otros autores ${ }^{29}$ han sido aún más precisos distinguiendo dentro del elemento jurídico dos subelementos: un elemento sería el jurídico, constituido por la calificación jurídica, razonamiento o fundamento jurídico, que vendría a ser el paso del hecho al derecho y que concretiza la pretensión; es el supuesto de hecho normativo que permite obtener la tutela solicitada. Y el otro elemento sería el puramente normativo, esto es, la invocación de las normas aplicables. De estos subelementos el primero forma parte de la causa de pedir, mientras que el segundo puede ser entregado al poder del juez.

\section{Críticas a las tesis tradicionales}

Con todo, estas teorías ya no gozan de muy buena fama. Parte de la doctrina las ha calificado de inútiles y erróneas ${ }^{30}$, y otros de insuficientes y de conducir a situaciones de genuina aporía ${ }^{31}$, destacando que por sí no logran explicar satisfactoriamente todos los fenómenos relacionados con el objeto del proceso. Se trata de doctrinas que siguen estando al arbitrio del intérprete.

No creo que estas teorías sean válidas para explicar en nuestro ordenamiento el poder del juez para aplicar el Derecho, menos aun en el marco del PCPC. En primer lugar porque las teorías de la individualización y sustanciación son completamente ajenas a nuestra práctica, escasamente conocidas por la doctrina y sin ningún reconocimiento jurisprudencial. En el derecho comparado han sido fuertemente criticadas y dada esa experiencia no parece recomendable extrapolarlas al PCPC. Además, por sí solas, nada resuelven, y únicamente trasladan el problema desde el ámbito de la libertad del juez en la utilización de los materiales jurídicos, hacia la determinación de cuál teoría es la que prima en el ordenamiento. En segundo lugar porque parece recomendable resolver legislativamente las materias en que son utilizadas estas teorías (cosa juzgada, litispendencia y modificación de la demanda), sin necesidad de recurrir a la interpretación que prefiera el operador de turno. Exigencias de seguridad jurídica justifican que el legislador haga el esfuerzo de regular completamente estos extremos.

Por otro lado, el PCPC ha abandonado completamente la categoría jurídica de "causa de pedir" como elemento identificador de la cosa juzgada y, al contrario, entrega la determinación de la identidad de las pretensiones directamente al juez, sin sujeción a requisitos o parámetros más allá de la necesaria identidad subjetiva. Con esta novedad ya ni siquiera es posible apelar a la causa de pedir como criterio delimitador de la utilización del Derecho.

\footnotetext{
${ }^{29}$ Tapia, I., El objeto del proceso. Alegaciones. Sentencia. Cosa juzgada, Editorial La Ley, Madrid, 2000, p. 24.

${ }^{30}$ Ibid., p. 22.

${ }^{31}$ De la Oliva, A., op. cit., p. 53.
} 


\section{Algunas claves para entender el poder DEl JUEZ PARA APLICAR EL DERECHo}

\section{Los problemas de la aplicación del Derecho}

Aun cuando esté superada la idea de que la adjudicación judicial constituye un ejercicio puramente silogístico, su idea permite reconocer y entender las complicaciones con que los tribunales de justicia suelen encontrarse al momento de escoger la premisa mayor. En el esquema silogístico el juez necesita encontrar la norma jurídica aplicable a los hechos probados para derivar las consecuencias jurídicas solicitadas por el demandante. Esa tarea, no obstante, suele presentar muchas dificultades, y puede ser una labor no del todo sencilla.

Uno de los problemas fácilmente identificables en la aplicación del Derecho es la existencia de contradicciones normativas, esto es, "dos normas que pertenecen a un mismo sistema, pero que no pueden ser aplicadas al mismo tiempo, con lo que se debe decidir cuál de las normas en conflicto será la aplicable"32. Este puede ser un problema con el que puede encontrarse un ciudadano al momento de justificar jurídicamente su pretensión, con la consecuente duda acerca del estatuto jurídico que resulta correcto. No resulta justo que el legislador traslade al ciudadano toda la responsabilidad de la elección de la norma jurídica (estatuto jurídico o institución jurídica) aplicable a la relación jurídica, más aún cuando ni el legislador da parámetros para resolver las antinomias y los criterios comúnmente utilizados no llevan a soluciones unívocas ${ }^{33}$. Por eso, la creación de alguna regla que permita al juez elegir la norma aplicable y someterla previamente a discusión de las partes es coherente con esas situaciones de antinomia.

Por otro lado, uno de los fenómenos que se ha instalado en los ordenamientos modernos ha sido el relativo a la "hiperinflación legislativa", caracterizado por la creciente proliferación de cuerpos legales y normas singulares destinadas a la regulación de relaciones jurídicas específicas o más complejas. A las normas jurídicas proclamadas en los códigos decimonónicos han devenido una serie de leyes especiales que han generado dinámicas y principios diversos. Desde luego que esta realidad ha producido una verdadera crisis de la ley, al fragmentar el ordenamiento, generando una casuística legislativa difícilmente compatible con los principios tradicionales, y acabando con todas las bondades de generalidad, permanencia y abstracción de las normas jurídicas.

De igual forma, la jurisprudencia ha contribuido considerablemente a la anarquía interpretativa, definiendo estatutos jurídicos incompatibles para el juzgamiento de unos mismos hechos ${ }^{34}$, colocando en jaque la previsibilidad y objetividad de las decisiones judiciales.

32 Moreso, J. y Vilajosana, J., Introducción a la teoría del Derecho, Marcial Pons, Madrid, 2004, p. 186.

33 Ibídem. La aplicación de los criterios de especialidad, jerarquía y temporalidad como mecanismos de solución de contradicciones normativas pueden llevar a soluciones dispares.

${ }^{34}$ Uno de los temas que sirve para reflejar en plenitud esta afirmación ha sido la responsabilidad por daños ocasionados en las concesiones de obra pública. El tratamiento de esta materia tiene dos características 
En este contexto, como explica la doctrina, el papel del juez se realza ${ }^{35}$, dado que no le es exigible al ciudadano una precisión en la alegación del Derecho cuando no ha existido previsibilidad de las decisiones de los tribunales, o cuando el ordenamiento está lejos de ser un todo orgánico, coherente y sistemático que facilite y garantice al ciudadano la protección de sus derechos.

Todo lo anterior trae como lógica consecuencia una fuerte dosis de inseguridad e incerteza jurídica al momento de fundamentar la pretensión, en la medida que resultan aplicables muchas normas conjunta o excluyentemente a la misma situación jurídica. Ciertamente esa imperfección del ordenamiento no debe ser soportada exclusivamente por el ciudadano. El legislador debe ser consciente de estas falencias y crear las herramientas adecuadas para corregir las imperfecciones jurídicas relacionadas precisamente con esa incerteza e inseguridad.

\section{La fundamentación jurídica como carga del justiciable}

Prácticamente todos los ordenamientos jurídicos condicionan la obtención de tutela al cumplimiento, por parte del ciudadano, de una serie de requisitos o presupuestos, dentro de los cuales podría encontrarse la fundamentación jurídica de la pretensión. Es el caso del Art. $253 \mathrm{~N}^{\circ} 4$ del PCPC que exige al actor narrar cada uno de los hechos que configuran la pretensión y el derecho en que se funda, norma similar al actual Art. 254 $\mathrm{N}^{\circ} 4$ del CPC. El problema podría surgir si se estima que el cumplimiento exacto de esta exigencia resulta esencial para la obtención de una tutela favorable, de manera que si el actor yerra en la fundamentación su pretensión se destina al fracaso.

No creo que ese sea el sentido correcto de la disposición. A mi juicio, esta norma consagra implícitamente dos exigencias diferentes: por un lado, la necesidad de individualizar o particularizar una determinada petición, y por el otro, la fundamentación jurídica ${ }^{36}$. En efecto, la particularización de una demanda supone relatar unos hechos que le dan vida, que la identifican y la distinguen de otras pretensiones ${ }^{37}$; en simples palabras, el actor debe alegar los datos necesarios e indispensables para identificar la pretensión de manera que adquiera autonomía, sin confundirse con otras posibles. Por

centrales: la primera es la gran cantidad de normas legales y reglamentarias, especiales y generales, que resultan paralelamente aplicables a los daños; y en segundo lugar, que la jurisprudencia ha postulado al menos cinco calificaciones jurídicas distintas respecto del estatuto aplicable a esa responsabilidad: responsabilidad indemnizatoria legal; responsabilidad contractual del derecho común; responsabilidad derivada de la infracción a los derechos del consumidor; responsabilidad extracontractual subjetiva del derecho común, y la responsabilidad por falta de servicio, sin perjuicio de entender que pueden darse casos de infracción a la ley del tránsito y a la ley de concesiones de obras públicas. Para un panorama completo: Diez, J., "Reparación y prevención de daños derivados de deficiencias viales en Chile: panorama normativo y jurisprudencial", en Revista de Derecho Universidad de Concepción, $\mathrm{N}^{\circ}$ 221-222, año LXXV, 2007, pp. 71 a 98.

35 Cfr., García de Enterría, E., El Derecho, la Ley y el Juez, Editorial Civitas, Madrid, 1997, p. 56.

${ }^{36}$ Vid., Berzosa, M., Demanda, "causa petendi" y objeto del proceso, Ediciones El Almendro, Córdova, 1984, p. 32 y ss.

${ }^{37}$ Ibid., pp. 32 y 33. 
ejemplo, en el caso de una demanda de resolución de contrato de compraventa por no pago de precio, el actor deberá indicar los sujetos que son parte del contrato, el objeto de la compraventa (cosa y precio), cuándo debía pagarse el precio y la afirmación de que se encuentra insoluto. Como se puede apreciar, se trata de una exigencia que corresponde esencialmente a la parte litigante, en la medida que la plena vigencia del principio dispositivo impide al órgano jurisdiccional aportar o considerar hechos jurídicamente relevantes ${ }^{38}$. Por ende, la tarea de dar vida a la pretensión, alegando los hechos que la individualizan, es una tarea esencialmente de los litigantes, en la cual el tribunal poco o nada puede hacer.

En cambio, fundamentar la pretensión consiste en apoyar su estimación en datos, argumentos y razones. Si bien la fundamentación puede comprender la alegación de hechos, es una función propiamente jurídica ${ }^{39}$, puesto que implica justificar la aceptación de una demanda a la luz del ordenamiento jurídico. En esta tarea el actor suele tener mucho que decir. Por lo general, se preocupará de seleccionar correctamente las normas que invocará, y de presentar su caso (particularización, individualización o identificación de la pretensión) de manera que naturalmente calce con las normas jurídicas invocadas. Sin embargo, no es necesario que el demandante acierte íntegramente en la fundamentación jurídica, pudiendo ser corregida o suplida por el órgano jurisdiccional. Esto se debe, a mi juicio, a la idea de que la fundamentación de la demanda es una carga procesal del ciudadano ${ }^{40}$, que deberá satisfacerse mínimamente pero no completamente para lograr el éxito querido por el actor.

No es este el lugar para dar cuenta del lugar protagónico que han ocupado las cargas procesales en el seno del proceso civil ${ }^{41}$. Sin embargo, se debe recordar que las teorías de las cargas procesales nacen con Goldschmidt como una forma de superar la tesis de la relación jurídica sustentada por Bullow. Para Goldschmidt las partes de un proceso se encuentran en una situación de expectativa respecto del fondo de la decisión, expectativa que se consuma favorablemente en la medida que se aprovechen las posibilidades procesales y se ejerciten las cargas. De igual forma, las posibilidades procesales serían las oportunidades que reconoce el ordenamiento para que el ciudadano desarrolle una determinada actividad dirigida a la obtención de un fin (la sentencia favorable), mientras que el cumplimiento de las cargas busca prevenir una situación procesalmente desventajosa (sentencia desfavorable) $)^{42}$.

Conforme esta escena, la exigencia de fundamentar jurídicamente una demanda por su carácter instrumental, facultativo y por estar destinada a satisfacer los intereses propios

38 Vid., por todos: Picó i Junoy, J., El derecho a la prueba en el proceso civil, Bosch Editor, Barcelona, 1996, pp. 212 y 213.

${ }^{39}$ Berzosa, M., op. cit., pp. 32 y 33.

${ }^{40}$ Vid., Golschmidt, J., Teoría general del proceso, Editorial Labor, Barcelona, 1936, pp. 82 y 83.

41 Al respecto puede verse: Fernández, M., La carga de la prueba en la práctica judicial civil, Editorial La Ley, Madrid, 2006, pp. 36 a 56, y así también: Gavazzi, G., L'onere. Tra liberta e l'obbligo, Giappichelli Editore, Torino, 1970, passim.

${ }^{42}$ Vid., Fernández, M., op. cit., p. 52. 
de quien propone el ingrediente jurídico, calza perfectamente con las características de la carga procesal ${ }^{43}$. El fin que busca la fundamentación jurídica de una demanda no es que el juez encuentre en ella los argumentos necesarios para acoger una demanda. Nada obliga al actor a justificar correctamente su pretensión -sí a individualizarla-, aun cuando plantear de entrada el debate en los parámetros jurídicamente correctos es una actividad que aumenta la posibilidad de que prospere la demanda. Es cierto que mientras más sean los argumentos jurídicos que el juez encuentre en la demanda para apoyar una decisión final favorable más posibilidades de éxito tendrá el actor. Pero el fin de la carga es la definición inicial de los términos jurídicos del conflicto, o en otras palabras, la determinación mínimamente correcta de los límites del debate jurídico ${ }^{44}$, lo que además "resulta por completo necesario para el funcionamiento de la administración de justicia, muy singularmente en un aparato judicial altamente burocratizado y que soporta elevados índices de sobrecarga de trabajo" ${ }^{45}$. Así como resulta contrario a la tutela judicial de los derechos e intereses entender que la tarea de alegación jurídica corresponde exclusivamente a las partes y vincula siempre al juez, también lo es descargar en el órgano jurisdiccional todo el trabajo normativo. El actor tendrá que "decir algo" mínimamente correcto respecto al derecho que estima aplicable, sin perjuicio de que en su totalidad no resulte vinculante para el juez.

Así entonces colocada la controversia en ese marco jurídicamente correcto el juez puede suplir la ausencia y corregir la errónea alegación del Derecho. Con todo, si el actor no cumple la carga de motivar jurídicamente la pretensión al extremo de que ésta no existe en lo más mínimo (no hay justificación jurídica), o bien la esgrimida sea oscura o simplemente ininteligible, el demandado puede oponer a la demanda la excepción previa de ineptitud del libelo (Art. $267 \mathrm{~N}^{\circ} 3$ PCPC). Con esto puede obligarse al actor a corregir su demanda so pena de tenerla por no presentada, pero en caso alguno puede considerarse una sanción derivada del no cumplimiento de una carga.

La segunda consecuencia es que el juez puede complementar las razones jurídicas esgrimidas por las partes. Nuevamente, la argumentación jurídica de la demanda no agota el espectro de razones posibles para fundar su acogimiento, y el tribunal puede agregar motivaciones que jurídicamente completen las iniciales. Por último, el tribunal

43 Ibid., pp. 47 a 56.

${ }^{44}$ El actor debe situar la controversia en un marco de mínima corrección jurídica, puesto que siempre será indispensable respetar la petición del ciudadano. Por ejemplo, si el ciudadano relata unos hechos que a su juicio justifican la nulidad de un contrato, cuando en realidad son típicos de un incumplimiento contractual, el juez no podrá salirse de los términos del debate jurídico pues concedería una cosa distinta a la pedida. Si el actor sitúa la controversia jurídica en extremos que nada tienen que ver con los hechos alegados como fundamento, es posible que el juez no pueda resolver favorablemente la pretensión ante la posibilidad de incurrir en vicios de ultra o extra petita. De ahí que sea importante cumplir con ese mínimo a que se hizo referencia.

En la clasificación de las cargas procesales postulada por Golschmidt la fundamentación mínimamente correcta correspondería a una carga perfecta, pues no puede suplirse por otro medio, como sería dando la posibilidad de que sea el juez el que redefina los términos correctos del debate jurídico. En cuanto carga perfecta se levanta con la indicación correcta del marco jurídico, pero ello no asegura el éxito de la pretensión. Cfr., Golschmidt, J., op. cit., p. 100.

45 Ormazábal, G., op. cit., p. 94. 
no queda ligado por las citas legales o jurisprudenciales que se hagan en una demanda, por ende, el error en que incurra el actor no impide la libertad del juez para buscar la norma aplicable a la controversia.

\section{La eficiencia del proceso y aplicación judicial del Derecho}

Para nadie es novedad que impartir justicia es caro y que la disponibilidad de los recursos destinados a satisfacerla es esencialmente limitada. En el caso de la Reforma al Proceso Civil chileno la opción por un proceso oral y público (artículos 6 y 9 PCPC), y que pueda orientarse a alcanzar decisiones verdaderas, tiene un alto costo o al menos uno superior al escrito. El proceso civil supone siempre una dualidad de costos que es necesario considerar al momento de diseñar su estructura y etapas: el costo para el sistema judicial y el del ciudadano que busca la protección de su derecho ${ }^{46}$. El Estado invierte una cantidad importante de recursos económicos cada vez que se produce un litigio; hay gasto material, de funcionamiento, de personal, costos para proporcionar una defensa gratuita adecuada, costos de oportunidad, etc. Por su parte, los ciudadanos también incurren en gastos: notificaciones, honorarios de peritos, abogados, búsqueda de la información relevante, etc. A esto hay que agregar los denominados "costes ocultos", que importan un conjunto de actividades económicas y sociales que no se materializan debido al mal funcionamiento de la justicia o los errores judiciales ${ }^{47}$. Esta realidad obliga al legislador a tener presente las consecuencias económicas del procedimiento para definir los caminos entre las diferentes instituciones o valores que puedan estar en pugna.

Dadas estas limitaciones en la utilización de los recursos es fácil darse cuenta lo deseable que es construir un proceso capaz de ser un cauce racional y económico que, sin olvidar su finalidad esencial, permita hacer frente a la demanda de justicia ${ }^{48}$. Y en este aspecto, dotar a los jueces de la posibilidad de aplicar ampliamente el Derecho parece una buena fórmula para hacer del proceso una herramienta económicamente eficiente ${ }^{49}$.

En efecto, las posibilidades de que un proceso pueda terminar con una sentencia que se limite, únicamente, a indicar que los materiales o normas jurídicas invocadas no

46 Vid., Pastor, S., “'Penuria de medios? Un análisis empírico de los costos públicos y privados visibles y ocultos de la justicia”, en La justicia procesal, Consejo General del Poder Judicial, VI, Madrid, 2008, pp. 347 a 434. Del mismo autor, puede verse muy especialmente: "El coste de la justicia: datos y un poco de análisis", en El coste de la justicia, Consejo General del Poder Judicial, Madrid, 2002, pp. 32 y 33.

${ }^{47}$ Ibíd., p. 414. Vid., además: Cooter, R. y Ulen, T., Derecho y economía, Fondo de Cultura Económica, México, 1997, p. 479 y siguientes, quienes identifican a los costos administrativos que son los propios de la litigación, y a los costos del error judicial, que son provocados por la litigación y que causan distorsiones en los incentivos e imponen costos en la sociedad.

${ }^{48}$ Explica Torres López, que "no es suficiente que los procedimientos judiciales se limiten a resolver los conflictos sino que ello debe hacerse conforme a los criterios y normas que regulan dichas instituciones, en el caso de la corriente mayoritaria conforme al postulado de la eficiencia (...) Ha de tratarse que el sistema de exigibilidad establecido minimice los costes que requiere su propio funcionamiento”. López, J., Análisis económico del Derecho, Tecnos, Madrid, 1987, p. 67.

${ }^{49}$ Vid., Hunter, I., "Rol y poderes del juez civil: una mirada desde la eficiencia del proceso”, op. cit., p. 45. 
son correctas es altamente probable cuando el poder del juez para aplicar el Derecho es reducido. En este caso, los esfuerzos económicos privados y estatales para dar tutela a un derecho o interés que efectivamente existe y que ha sido lesionado resultan infructuosos, por la única razón de que se ha invocado una norma o institución incorrectamente. Se ha tramitado un largo y costoso proceso que ha resuelto un conflicto pero que no ha dado la tutela a quien efectivamente la merece bajo normas diversas a las invocadas.

Por lo general, las sentencias que sustentan su decisión en la incorrecta apreciación de la norma producen efectos perversos desde el punto de vista económico. Es verdad que todo fallo judicial resuelve con vocación de perpetuidad una controversia; sin embargo, cuando ésta se basa en una incorrecta aplicación del Derecho existe la legítima tentación de renovar la controversia con una nueva demanda fundada en otra calificación jurídica, justificando que entre uno y otro proceso no habría una idéntica causa de pedir. Por ejemplo, el fallo determina una responsabilidad del tipo contractual habiendo sido invocada la responsabilidad aquiliana; no cabe duda que el ciudadano volverá a accionar esgrimiendo la otra clase de responsabilidad. Con esto, se produce un costo social ligado a la sobrelitigación, al tener el sistema judicial que preocuparse nuevamente del mismo conflicto, con la consecuente paralización de los bienes jurídicos que son su objeto ${ }^{50}$. De esta forma, si el costo de la pretensión no supera el que incurre el litigante, aun es factible, económicamente hablando, recurrir al proceso civil, máxime si el costo del sistema judicial no es absorbido por el ciudadano.

Por el contrario, si el órgano jurisdiccional está plenamente legitimado para corregir, suplir o modificar los planteamientos jurídicos erróneos, entonces la posibilidad de que ese proceso culmine con una sentencia que se pronuncie sobre la existencia del derecho y su lesión es altamente probable. Aquí los costos invertidos permitirán la eficiencia del proceso desde la óptica del Derecho aplicable, pues el juez no podría rechazar una pretensión por estar jurídicamente mal fundada. Por ejemplo, si se reclama la responsabilidad contractual de una empresa, y el juez estima que ese estatuto jurídico ha sido mal invocado, puede acoger la pretensión fundando el fallo en la responsabilidad aquiliana.

En esta ecuación es sencillo comprender lo esencial que es definir el rol del juez. Si se trata de evitar que un proceso largo, costoso y tedioso culmine con una sentencia que explique la inadecuada aplicación del Derecho es razonable entender que el juez debe tener la posibilidad de reconducir la calificación jurídica en el cauce jurídico correcto.

Razones de eficiencia del proceso permiten justificar la creación de alguna regla procesal que permita someter a la contradicción de las partes una nueva calificación, de manera de evitar una sentencia netamente jurídica que se limite a rechazar la demanda cuando los materiales jurídicos han sido mal invocados. Se trata de hacer efectivo el

${ }^{50}$ En un Estado Constitucional de Derecho se asegura a los ciudadanos el libre acceso a los tribunales de justicia, de manera que los costos del sistema judicial asociados a la litigación no son asumidos por los usuarios. Esto, por cierto, genera un efecto perverso respecto de la litigación, puesto que no hay incentivos ligados a la diminución de los litigios. No obstante, me parece que la opción por establecer barreras de acceso a la jurisdicción como mecanismo de desincentivo a la litigación es, al menos, "sospechosa" desde el punto de vista de su constitucionalidad, lo que produce la necesidad de encontrar otras herramientas. 
derecho de defensa de las partes en el debate estrictamente jurídico, con la finalidad de facilitar la dictación de una sentencia que resuelva definitivamente la controversia, corrigiendo la errónea calificación efectuada por el actor.

Esta regla viene a constituirse en un desincentivo importante a la proliferación de nuevos litigios; si el juez puede corregir la aplicación del Derecho en vez de limitarse a indicar en la sentencia su incorrecta invocación, la posibilidad de que se produzca un nuevo juicio es altamente poco probable. Esta opción me parece que es constitucionalmente permitida y al menos es una herramienta que directamente desincentiva el litigio, sin cuestionar la posibilidad del ciudadano de acceder a la jurisdicción.

\section{LA CONTRADICCIÓN: ¿LÍMITE O PRESUPUESTO DE LA APLiCACión JUdiCial DEL DERECHO?}

De acuerdo a la postura que tradicionalmente se ha sostenido ${ }^{51}$, el juez civil no tiene por qué someter a escrutinio de las partes su opinión jurídica antes de la decisión, como tampoco las cuestiones o actuaciones que está llamado a efectuar de oficio. El tribunal actúa en cuanto órgano del Estado dotado de poder, cuya única obligación es fundamentar su decisión en el Derecho y no necesita escuchar al ciudadano en los aspectos netamente jurídicos de la decisión para legitimarla.

No obstante, en el ámbito comparado la doctrina no tardó en reconocer al derecho de defensa como un límite al poder del juez en la aplicación del Derecho ${ }^{52}$. Se explica por los autores, "los reparos en relación al derecho de defensa se centran en lo novedoso

51 En contra: Hunter, I., "Iura novit curia en la jurisprudencia civil chilena”, op. cit., pp. 217 a 219, quien propone interpretar los artículos 160 y 768 No 4 CPC como exigencia de congruencia de las resoluciones judiciales, en el sentido de que el juez no puede salirse de los extremos en que las partes han planteado el debate para acoger una demanda.

52 Vid., Ormazábal, G., op. cit., pp. 105 y siguientes; Normand, J., "I poteri del giudice e delle parti quanto al fondamento delle pretensa controverse” en Rivista di Diritto Processuale, Vol. XLIII, p. 740; Garnica, J., "El principio iura novit curia y la determinación del objeto del proceso en el Proyecto de reforma de la Ley de Enjuiciamiento Civil" en La Ley, tomo I, 1999, pp. 1715 y siguientes; Yllesca, R., "El principio iura novit curia y la posición del abogado en el proceso" en La Ley, $\mathrm{N}^{\circ} 3$, 1994, pp. 832; Trocker, N., Processo civile e costituzione. Problemi di diritto tedesco e italiano. Giuffrè Editore, Milán, 1974, pp. 645 y 682; Ortells, M., "Principio acusatorio, poderes oficiales del juzgador y principio de contradicción. Una crítica de cambio jurisprudencial sobre corrección entre acusación y sentencia" en Justicia 91, N 4, 1991, p. 782; Tarzia, G., "Poteri delle parti e poteri del giudice" en Problemi del processo civile di cognizione, Cedam, Padova, 1989, p. 318; Ferri, C., "Sull'effetività del contraddittorio" en Rivista Trimestrale di Diritto e Procedura Civile, Vol. LXIII, No 2, p. 793. También hay variantes que encontraron en el contradictorio un límite pero sólo cuando su omisión impedía el ejercicio de una defensa efectiva de las partes, más que la omisión del debate. En este caso la determinación de la indefensión supone una mirada retrospectiva, debiendo colocarse el juez al momento de la sentencia para definir si efectivamente, de haber existido contradicción, la decisión hubiese sido distinta. Vid., Chiarloni, S., "Questioni rilevabili d'ufficio, diritto di difesa e 'formalismo delle garanzie". Rivista Trimestrale di Diritto e Procedura Civile. XLI, No 1 , pp. 583 y ss. 
y sorpresivo del punto de vista jurídico con el que se presenta la condena y en relación con el cual el demandado nada pudo alegar u objetar durante el proceso ${ }^{53}$ ".

De esta forma, resulta clave para determinar el alcance del poder del juez en la utilización de las normas jurídicas definir el papel que debe jugar la contradicción. En esta temática me atrevo a sostener la existencia de dos versiones o formas de entender la contradicción que tienen especial importancia en este tema, y marcan un ámbito diferente de actuación del juez en la utilización del Derecho.

En una primera aproximación la contradicción constituía un límite a la vigencia de la máxima iura novit curia, de manera que si bien el juez tiene el control en la selección de las normas aplicables, esa actividad se encuentra limitada por la contradicción. Se trata, por tanto, de una libertad restringida, pues el juez puede razonar, buscando y aplicando las normas jurídicas apropiadas, siempre y cuando mueva sus razonamientos en el ámbito de las cuestiones jurídicas planteadas por las partes ${ }^{54}$. De esta manera, el respeto por la contradicción impide al juez pronunciarse favorablemente sobre una pretensión cuando los argumentos o posiciones jurídicas no habían sido objeto del debate. La posibilidad de negar a un ciudadano la tutela de un derecho por la incorrecta invocación de las normas jurídicas es altamente probable.

Esta visión del contradictorio primó en buena parte de los ordenamientos hispanoparlantes al relacionarse con la idea de paridad de armas. El juez debía restarse completamente del contradictorio, y éste se produce con la finalidad de enfrentar dialécticamente las tesis de las partes que -situadas en un plano de igualdad-, debaten frente y para un juez. La decisión, no obstante, podía ajustarse o no a lo previamente discutido, pudiendo perfectamente desligarse del debate en los aspectos jurídicos. El tribunal no puede resolver sin que se haya dado la posibilidad a las partes de alegar, dialécticamente y en situación de igualdad, sus posiciones jurídicas, pero nada aseguraba que la decisión vaya a fundarse estrictamente en el producto de ese debate.

Hoy en día, sin embargo, el contradictorio tiene un alcance mucho más extenso, y aparece destinado a reglamentar las relaciones entre el individuo y el Estado (ya no solo entre los individuos), tutelando al ciudadano de cara a la iniciativa de la autoridad (el juez) en el ejercicio de su función soberana. El derecho de defensa, por su parte, es concebido como una garantía de los litigantes frente a los poderes atribuidos al juez, asumiendo una diferencia conceptual respecto a la igualdad de armas ${ }^{55}$. De esta forma, el contradictorio pasa a estar integrado por dos fases: por un lado, organiza las relaciones respecto a cada una de las partes entre sí, y por la otra, disciplina la relación del Estado

53 Ormazábal, G., op. cit., p. 106.

${ }^{54}$ Ezquiaga, F., op. cit., p. 31; Carreras, J., "Facultades materiales de dirección”, en Estudios de Derecho Procesal (con Fenech, Miguel), Librería Bosch, Barcelona, 1962, p. 257, e Yllesca, R., op. cit., p. 832.

55 Esta visión del contradictorio ha calado hondo especialmente en la doctrina italiana, que a la par del aumento de los poderes del juez ha robustecido el ejercicio de la contradicción. Así, entre otros: Andolina, I. y Vignera, G., I fondamento costituzionale della giustizia civile. Il modello costituzionale del processo civile italiano, Giappicchelli Editore, Torino, 1997, p. 74; Verde, G., Profili del proceso civile. Parte generale, $2^{\mathrm{a}}$ edición, Jovene Editore, Nápoles, 1988, p. 97, y Comoglio, L., "Giuridizione e proceso nel quadro delle garanzie costituzionali" en Rivista Trimestrale di Diritto e Procedura Civile, Vol. XLVIII, No 4, 1994, p. 1085. 
con el individuo. Así entendida, la contradicción es concebida como el derecho del justiciable de influenciar y participar en el ejercicio del poder del Estado, siendo necesariamente previo a cualquier decisión jurisdiccional, y esencial para la legitimación de la decisión justa ${ }^{56}$.

En esta mirada el órgano jurisdiccional participa junto a las partes en el debate de los extremos de la decisión, de manera que su opinión acerca de la utilización de los materiales jurídicos debe ser objeto de discusión como si se tratara de la opinión del actor o del demandado. El juez asume el deber de promover el contradictorio entre los sujetos del proceso sobre todos los aspectos jurídicos relevantes, especialmente en aquellos que desea considerar de oficio. De esta forma, la contradicción deja de ser una cuestión de dos (actor y demandado) para convertirse en un diálogo de tres sujetos (demandante, demandado y juez). Las partes pueden cuestionar e influenciar la posición jurídica con que se pretende resolver la controversia, pudiendo de esa manera arribar a una decisión más justa. La decisión, en los aspectos estrictamente normativos, pasa a ser el resultado de la colaboración y participación de las partes y el juez, esto es, un actus trium personarum $^{57}$. Es además una forma sensata de evitar que el juez pueda incurrir en algún error de apreciación jurídica, puesto que las partes tendrían la opción de reflexionar acerca del Derecho aplicable antes de la decisión.

Para esta segunda variante, resulta imposible cuestionar la libertad del juez en la aplicación del Derecho, siendo tarea de éste definir la calificación jurídicamente correcta. Por consiguiente, el enfoque debe centrarse no tanto en ese poder, sino más bien "cómo los ejercita" para no perjudicar el derecho de defensa ${ }^{58}$. En consecuencia, para esta corriente doctrinal se hace necesario promover irrestrictamente el ejercicio del contradictorio en todos los extremos jurídicos de la controversia como mecanismo de legitimación de la decisión judicial, de manera de evitar que las partes se vean sorprendidas por lo resuelto por el juez en la sentencia definitiva ${ }^{59}$. Para cumplir este objetivo el rol del legislador es el de crear las instancias o momentos procesales para que las partes puedan en igualdad y contradictoriamente discutir respecto del nuevo punto de vista jurídico con que el juez pretende resolver el litigio. De esta forma, el centro de atención deja de ser la pertinencia y legitimidad de la "opinión divergente del juez", y se traslada hacia la articulación de un sistema que permita al justiciable opinar sobre esa calificación u opinión antes de dictar la sentencia ${ }^{60}$.

\footnotetext{
${ }^{56}$ Cabral, A., "Il principio del contraddittorio como diritto d'influenza e dovere di dibattito" en Rivista di Diritto Processuale, Vol. LX, No 2, 2005, p. 450 y siguientes, y Comoglio, L., "Giuridizione e proceso nel quadro delle garanzie costituzionali”, op. cit., p. 1085.

57 Vid., Verde, G., op. cit., p. 97; Picardi, N., "Il principio del contraddittorio", en Rivista di Diritto Processuale, Vol. LIII, No 3, 1998, p. 680; Tarzia, G., op. cit., p. 319, y Comoglio, L., "Giuridizione e proceso nel quadro delle garanzie costituzionali”, op. cit., p. 1085.

58 Almagro, J., "Garantías constitucionales del proceso civil", Para un proceso civil eficaz. Universidad Autónoma de Barcelona, Barcelona, 1982, p. 29.

59 Ibidem.

${ }^{60}$ Trocker, N., op. cit., p. 683.
} 
Esta última visión del contradictorio ha empapado el espíritu de las reformas legislativas en países como Alemania ( $\$ 139$ ZPO), Francia (Art. 16 inciso $3^{\circ}$ ) y Austria (\&182 ZPO). Estas legislaciones han robustecido los poderes de los jueces en todos los ámbitos del proceso (hechos, prueba, impulso y aplicación del Derecho) pero, al mismo tiempo, se ha exigido que respete irrestrictamente el contradictorio previo cuando quieren decidir apartándose a lo debatido en el proceso. Esta tendencia no es ajena en nuestro país. El Código Procesal Penal en su artículo 341 inciso $3^{\circ}$ establece el deber de contradicción cuando el Tribunal Oral en lo Penal pretende resolver en base a una calificación jurídica diversa a la discutida en el proceso, evitando, de ese modo, una decisión sorpresa. Lo mismo que la Ley Orgánica del Tribunal Constitucional que en su artículo $57^{61}$ dispone que el tribunal puede resolver apartándose de los fundamentos normativos esgrimidos por las partes, permitiéndole a éstas referirse a ellas.

En consecuencia, el deber de respetar el contradictorio es una manifestación clara de que el juez no tiene el dominio absoluto de los materiales jurídicos ${ }^{62}$, y en esa medida se justifica la presente investigación.

\section{Propuesta de un modelo de aplicación Judicial DEL DERECHO PARA PCPC, LÍMITES Y SITUACIONES}

A lo largo del trabajo he tratado de justificar un poder amplio del juez en la aplicación de los materiales jurídicos. En lo que sigue pretendo sugerir un modelo que permita hacer compatible el derecho de defensa de los justiciables y la tutela judicial efectiva. Se trata de que el proceso que se inicia pueda finalizar con una sentencia del fondo que no se limite a indicar el yerro del actor en el modo de proponer los materiales jurídicos de la pretensión. Para esto es necesario definir el momento adecuado para que el juez pueda recalificar la pretensión impulsándola al cauce jurídicamente correcto y, al mismo tiempo, someterla a discusión de las partes.

\section{Situaciones de divergencia entre la calificación jurídica propuesta por el actor y la del juez}

Es indispensable efectuar una serie de matices en relación a la divergencia que puede darse entre la calificación del actor y la que hace el juez en su sentencia definitiva. Esta puede producirse por tres razones ${ }^{63}$ :

${ }^{61}$ Esta norma dispone: "Artículo 57. Excepcionalmente y por razones fundadas, el Tribunal podrá declarar la inconstitucionalidad de las normas cuestionadas basado únicamente en fundamentos constitucionales distintos a aquellos que han sido invocados por las partes en la litis. En este caso, deberá advertirles acerca del uso de ese posible precepto constitucional no invocado y permitirles así referirse a ello. Dicha advertencia podrá efectuarse en cualquier etapa del juicio, incluyendo la audiencia de la vista de la causa, cuando proceda, y también como medida para mejor resolver".

62 Normand, J., op. cit., p. 1988.

${ }^{63}$ Excluyo de esta exposición la situación poco frecuente pero no por ello imposible de que las partes no hayan calificado jurídicamente los hechos, y se limitan a discutir acerca de la existencia de los hechos 
a) Los hechos alegados por el actor no caben en los presupuestos de las normas que se alegan como aplicables a la relación controvertida. Aquí hay un problema de adscripción de hechos a normas jurídicas. Ninguna de las circunstancias empíricas y concretas alegadas por el actor corresponde a los supuestos abstractos y generales descritos en la norma que se estima y esgrime como aplicable. Esto puede deberse a diversas causas: yerro del litigante, texto legal semánticamente abierto, texto legal imperfecto, etc. El proceso se desarrolla en términos normales, y resultan efectivamente probados los hechos alegados por el actor; sin embargo, no pueden ser adscritos en los supuestos fácticos de las normas jurídicas que permiten conceder el efecto pedido. En este caso el problema de calificación nace con la interposición misma de la demanda.

Este supuesto podría ser resuelto de dos maneras: dando la posibilidad de que el juez se desligue completamente de la calificación propuesta, dándole a la pretensión la que estime correcta; o bien rechazando la demanda fundada en la incorrecta calificación jurídica.

b) El juez, en la sentencia definitiva, considera como jurídicamente relevantes algunos hechos que para las partes no lo son y que tienen el carácter de secundarios ${ }^{64}$, siempre y cuando hayan sido afirmados en la demanda. Por ejemplo, se pide la nulidad de un contrato, aludiendo dentro de los hechos que la justifican la demencia de una de las partes. El juez en la sentencia declara la nulidad del contrato por simulación, considerando otros hechos alegados en la demanda como jurídicamente relevantes. La sentencia respeta la petición concreta (nulidad de un contrato) pero utiliza hechos distintos a aquellos con que el actor fundamentó su demanda. El desarrollo del proceso también es normal, y únicamente se produce el cambio en el criterio de relevancia con que la parte introdujo o alegó un hecho. A diferencia del caso anterior, la demanda está correctamente planteada y no hay problemas de adscripción de hechos a normas, aun cuando es posible entender que el actor también pudo plantear su pretensión tomando como base el hecho secundario, invocando las normas jurídicas que le resultaban aplicables. Aquí el desajuste entre la calificación propuesta y la que efectivamente sustenta la sentencia se produce en la sentencia misma.

c) La tercera posibilidad en que puede darse esta divergencia sucede cuando los hechos declarados probados por la sentencia calzan con otras normas o instituciones jurídicas no invocadas, y que el juez decida calificar la pretensión conforme a ellas. Del conjunto de hechos afirmados por el actor para alcanzar el efecto pedido solo

sin entrar a fondo en el debate jurídico. Esta hipótesis podría estar cubierta por la excepción priva de ineptitud del libelo.

${ }^{64}$ En el ámbito del derecho nacional la categoría de hechos secundarios no sido conocida por la doctrina y jurisprudencia. Esto contrasta con el desarrollo que ha tenido en el Derecho Comparado. Los hechos secundarios se distinguen de los principales en la medida que no reciben calificación jurídica, y adquieren relevancia en el proceso en la medida que se pueden extraer argumentos a favor o contra de la verdad de un enunciado principal. Vid., Taruffo, M., La prueba de los hechos, Editorial Trotta, Madrid, 2009, p. 120. 
resultan acreditados algunos que no son suficientes para sustentar la aplicación de las normas jurídicas invocadas como fundamento, pero que permiten la aplicación de otras. Por ejemplo, se demanda la responsabilidad contractual de una empresa, no lográndose acreditar el vínculo contractual, pero sí los demás supuestos de la responsabilidad civil. En este caso el juez podría acoger la demanda justificando su decisión en la responsabilidad aquiliana. En este supuesto no hay problemas de adscripción de hechos a normas, sino de acreditación de todos los hechos que permiten identificar las normas aplicables.

Para evitar estas situaciones no siempre es posible apostar por un modelo único de aplicación judicial del Derecho, cuyo propósito será evitar, o al menos disminuir, las posibilidades de que el juez sorprenda a las partes con una nueva calificación, o que la sentencia se limite a indicar que el Derecho fue incorrectamente aplicado ${ }^{65}$.

\section{De lege ferenda: la audiencia previa como momento procesalmente adecuado para la recalificación jurídica}

Creo que el momento adecuado para corregir las imperfecciones en materia jurídica no puede ser otro que la audiencia preliminar, instante en que el juez podría proponer una nueva calificación a la pretensión. La principal razón para estimar la conveniencia de este momento es la estrecha relación que debe existir entre las normas jurídicas aplicables y la determinación de los hechos que serán objeto de la actividad probatoria. Resulta indispensable para el orden del contradictorio y la congruencia del juicio que los hechos que deben ser objeto de la prueba (incluidas las convenciones probatorias, los hechos notorios, o que no son controvertidos) coincidan íntegramente con los supuestos de hecho de los materiales que potencialmente resultan aplicables.

En el proceso civil chileno corresponde la carga de probar los fundamentos de hecho contenidos en una norma jurídica a la parte cuya aplicación beneficie (Art. 294 PCPC), de manera que parece necesario compatibilizar esa carga procesal con la posibilidad de modificar los elementos normativos invocados en el juicio, que son, precisamente, los que sirven para identificar los hechos objeto de la prueba. Es el marco jurídico el que define qué hechos son los procesalmente relevantes, de manera que no puede precisarse la controversia fáctica sin antes definir cabalmente ese marco ${ }^{66}$. De acuerdo al PCPC el juez en la audiencia preliminar tiene como misión fijar tanto el asunto controvertido como los hechos sustanciales y controvertidos que serán objeto del litigio (Art. 280 $\mathrm{N}^{\text {os }} 6$ y 7). Por lo mismo, es el momento ideal para definir, previamente, los aspectos jurídicos que sea necesario corregir o modificar.

\footnotetext{
${ }^{65}$ Hay que señalar que también es posible apartarse de soluciones que corrijan la imperfecta invocación del derecho; es el caso del rechazo in limine de la demanda cuando una pretensión está jurídicamente mal planteada, donde el legislador lejos de permitir al juez recalificar la posición jurídica del demandante le ordena rechazarla en la entrada del juicio cuando estime que éste carece de manifiesto fundamento. Esta institución es algo ajena a nuestro proceso civil, y únicamente es posible encontrarla en el Art. 154 de la Ley de Tribunales de Familia.

${ }^{66}$ Ormazábal, G., op. cit., pp. 125 y 126.
} 
Esto implica la necesidad de plantear una reforma al PCPC, incorporando una regla que permita someter a debate en todos sus extremos la calificación propuesta por el juez. Para tal efecto, propongo el siguiente sistema:

a) Un poder general en la audiencia preliminar para advertir a las partes la posibilidad de que la demanda encuentre sustento en otra calificación jurídica diferente a la sustentada por el actor al momento de deducirla. Esta advertencia no supone un cambio en la calificación jurídica a instancias del demandante, sino la posibilidad de discutir y controvertir la calificación que el juez pretende introducir para resolver favorablemente la controversia. Efectuada esta advertencia, el tribunal podría acoger la demanda fundándola en esta nueva calificación. Con este modelo se evita la situación descrita con la letra a) del numeral 1 precedente, al permitir realizar la adscripción correcta de hechos a norma jurídica.

Este poder no es limitado, ya que el juez no puede dar una cosa diferente a la pedida. Si así lo hiciera incurría en el vicio de extra petita (Art. 381 letra d)). En efecto, cuando el ciudadano pretende un efecto jurídico afirma la existencia de unos hechos que integran el presupuesto de la norma que fundamenta y hace posible ese efecto. Si el ordenamiento no permite conceder la tutela en base a los hechos alegados entonces el juez queda inmediatamente restringido en su ámbito de aplicación del Derecho. La intangibilidad de la petición como manifestación del principio dispositivo sí provoca un efecto delimitador de los materiales jurídicos que se pueden utilizar para conceder la tutela pedida ${ }^{67}$.

Por otra parte, el juez no está en el deber de promover el contradictorio cuando su decisión se basará estrictamente en los términos del debate, como sería el caso en que la controversia versa exclusivamente sobre aspectos jurídicos. Se trata de situaciones donde las partes aceptan los hechos, y discuten acerca de su calificación jurídica. Por ejemplo, ambos litigantes están de acuerdo en la existencia de un mandato, sus términos y condiciones, situando la controversia en la naturaleza civil o comercial de éste. El demandante lo califica de mandato civil, mientras que el demandado de comercial, con las diversas consecuencias de una u otra calificación, entre ellas, la prescripción de las acciones.

Con todo, este poder operará siempre que el actor haya fundamentado incorrectamente su pretensión, y la advertencia que pueda hacer el juez permita acoger la demanda bajo argumentos jurídicos diversos. Por ende, no procede cuando la correcta fundamentación de la pretensión impide acoger la demanda en los términos que fue planteada.

b) En la misma audiencia preliminar el juez puede advertir a las partes el cambio de relevancia de los hechos propuestos, con la finalidad de discutir sobre los mismos. Desde luego, en esta situación las partes se han equivocado respecto a qué hecho han querido situar como base de su pretensión, colocando a otro como jurídicamente

${ }^{67}$ Ibíd., p. 88 y Hunter, I., "Iura novit curia en la jurisprudencia civil chilena”, op. cit., p. 209. 
relevante ${ }^{68}$. Aquí el juez puede sugerir a las partes que determinado hecho indicado en la demanda ${ }^{69}$ pase a constituir la base de la pretensión puesto que permite derivar las consecuencias jurídicas solicitadas. En cierta forma, lo que hace el juez es trasladar, mediante una concreta calificación jurídica, la indicación de un hecho a la categoría de alegación de un hecho ${ }^{70}$, cuando el actor ha cometido un yerro en su adscripción. Con este modelo se evita la situación descrita con la letra b) del numeral 1 precedente, al permitir realizar el cambio en la relevancia jurídica del hecho y someterla a contradicción de las partes.

c) Por último, luego de practicada la prueba, siempre será posible que el juez pida a las partes referirse a algún punto jurídico que pueda ser discutible o que no haya sido objeto de discusión, pero no puede modificar los fundamentos jurídicos de la pretensión.

\section{CONCLUSIONES}

Uno de los aspectos que no ha sido abordado por el PCPC es la extensión de los poderes del juez en relación a la aplicación del Derecho. Es una verdadera nebulosa determinar si el juez puede apartarse de los materiales jurídicos propuestos por las partes como fundamento de su demanda, y acoger la pretensión en base a otros no invocados. En ese contexto, las explicaciones tradicionales elaboradas por la doctrina para explicar este fenómeno no han sido fructíferas, recibiendo una fuerte crítica por su evidente dispersión, y por trasladar el problema de fondo hacia otros extremos, como la causa de pedir, el objeto del proceso, etc. En nuestro ordenamiento esas explicaciones son aún más precarias, y difícilmente pueden generar un consenso en los operadores al momento de decidir si existe o no la posibilidad de deslingarse de los fundamentos jurídicos de la demanda. Hay, por tanto, evidentes razones de seguridad jurídica y economía procesal que justifican un esfuerzo doctrinal y legislativo para consagrar una regla que permita someter al debate de las partes la calificación con que el juez pretende resolver la controversia.

${ }^{68}$ La definición de qué hecho o hechos del conjunto alegado por el actor determina la aplicación de una norma jurídica por sobre otra, es una cuestión que queda entregada al juez conforme las prescripciones del derecho material. Por tal motivo, el cambio de relevancia de los hechos cuando la calificación propuesta ha sido errónea no implica mutar la naturaleza de la acción, ni pasar por sobre la voluntad del demandante. En cierta forma, para obtener la tutela solicitada por el actor el juez modifica la relevancia con que son introducidos los hechos.

${ }^{69} \mathrm{La}$ indicación de un hecho consistiría en la exposición consciente de un determinado acontecimiento, sin atribuirle ningún contenido o valor jurídico específico. Esta hipótesis queda plenamente cubierta con esta posibilidad, en que el juez puede dar a esos hechos la calificación jurídica correspondiente, apartándose a la propuesta por el actor. Vid., Buoncristiani, D. L'allegazione dei fatti nel processo civile. Profili sistematici, Giappichelli Editore, Torino, 2001, p. 26.

${ }^{70} \mathrm{La}$ alegación de un hecho consiste en la atribución de un valor jurídico determinado a un acontecimiento para producir un efecto jurídico también determinado. Ibídem. 
En este sentido la idea de que el proceso civil tiene por finalidad la tutela de los derechos de los ciudadanos más que la pura resolución de un conflicto, coadyuva considerablemente a entender que la judicatura debe jugar un rol activo en la aplicación de las normas jurídicas. No resulta sensato que la efectividad de una actividad eminentemente pública como la jurisdicción deba quedar entregada a la correcta invocación por parte del ciudadano del estatuto jurídicamente aplicable. Esta falta de sensatez se refuerza si se asume que nos encontramos inmersos en un verdadero proceso de "hiperinflación" legislativa (con la consecuente carencia de racionalidad legislativa) y falta de coherencia de las decisiones judiciales. El esfuerzo por encontrar el estatuto aplicable a una controversia puede no conducir al resultado querido, precisamente por los inconvenientes que implica la existencia de una frondosa legislación.

Por eso es imprescindible entender que la fundamentación jurídica de una demanda es una carga procesal, que únicamente coloca al ciudadano en la necesidad de situar la controversia en un marco mínimamente correcto dentro del cual el juez es libre para desplegar su argumentación. Esta posibilidad, no obstante, está sujeta al límite del respeto del derecho de defensa, debiendo someterse a la contradicción de los fundamentos jurídicos con que se pretende resolver la controversia. Para ello es necesario crear una regla que permita al juez, conjuntamente con las partes en la audiencia preliminar, discutir los aspectos jurídicos que sea necesario introducir para conducir la demanda hacia el camino jurídicamente correcto.

\section{BiBLIOGRAFÍA}

Andolina, I. y Vignera, G., I fondamento costituzionale della giustizia civile. Il modello costituzionale del processo civile italiano, Giappichelli Editore, Torino, 1997.

Berzosa, M., Demanda, "causa petendi" y objeto del proceso, Ediciones El Almendro, Córdoba, 1984.

Bordalí, A., "Justicia del proceso y de la sentencia civil", en La reforma Procesal Civil en Chile, Cuadernos de Extensión Jurídica 16, Universidad de los Andes, Santiago, 2009, pp. 77-99.

Buoncristiani, D., L'allegazione dei fatti nel processo civile. Profili sistematici, Giappichelli Editore, Torino, 2001.

Cabral, A., "Il principio del contraddittorio como diritto d' influenza e dovere di dibattito" en Rivista di Diritto Processuale, Vol. LX, No 2, 2005, pp. 449-464.

Carreras, J., "Facultades materiales de dirección” en Estudios de Derecho Procesal (con Fenech, Miguel), Librería Bosch, Barcelona, 1962, pp. 255-264.

Comoglio, L., "Giuridizione e proceso nel quadro delle garanzie costituzionali" en Rivista Trimestrale di Diritto e Procedura Civile, Vol. XLVIII, No 4, 1994, pp. 1065-1111.

Comoglio, L., "I modeli di garanzia costituzionale del proceso" en Rivista Trimestrale di Diritto e Procedura Civile, año XLV, No 3, 1991, pp. 673-741.

Cooter, R. y Ulen, T., Derecho y economía, Fondo de Cultura Económica, México, 1997.

Cortés, V., "La eficacia del proceso de declaración", en Constitución, Derecho y Proceso, Estudios en memoria de los profesores Vicente Herche Quemada y Ángel Duque Barragues. Zaragoza, Facultad de Derecho Universidad de Zaragoza, 1983, pp. 385-408.

Damaska, M., Las caras de la justicia y del poder del Estado. Análisis comparado del proceso legal, Editorial Jurídica de Chile, Santiago, 2000. 
Damián, J., "La fase de alegaciones", en Hacia una nueva justicia civil, Fundación El Monte, Sevilla, 1998, pp. 59-77.

De la Oliva, A., Objeto del proceso y cosa juzgada en el proceso civil, Thomson Civitas, Madrid, 2005.

Díaz, J., Principios de aportación de parte y acusatorio: la imparcialidad del juez, Editorial Comares, Granada, 1996.

Diez, J., "Reparación y prevención de daños derivados de deficiencias viales en Chile: panorama normativo y jurisprudencial”, en Revista de Derecho Universidad de Concepción, No 221-222, año LXXV, 2007, pp. 71 a 98.

EzQuiaga, F., Iura novit curia y aplicación judicial del derecho, Editorial Lex Nova, Valladolid, 2008.

Fernández, M., La carga de la prueba en la práctica judicial civil, Editorial La Ley, Madrid, 2006.

Ferri, C., "Sull'effetività del contraddittorio" en Rivista Trimestrale di Diritto e Procedura Civile, Vol. LXIII, No2, pp. 780-795.

Garapon, A. y Papadopoulos, I., Juzgar en Estados Unidos y en Francia. Cultura jurídica francesa $y$ common law, Editorial Legis, Bogotá, 2008.

GARNICA, J., "El principio iura novit curia y la determinación del objeto del proceso en el Proyecto de reforma de la Ley de Enjuiciamiento Civil” en La Ley, tomo I, 1999, pp. 1713-1716.

Gavazzi, G., L'onere. Tra liberta e l'obbligo, Giappichelli Editore, Torino, 1970.

Gimeno, V., Derecho procesal civil. I. El proceso de declaración. Parte general. Segunda edición, 2007, Colex, Madrid, 2007.

Golschmidt, J., Teoría general del proceso, Editorial Labor, Barcelona, 1936.

Hunter, I., "Iura novit curia en la jurisprudencia civil chilena", en Revista de Derecho de la Universidad Austral de Chile, Vol. XXIII, N² 2, 2010, pp. 197-221.

Hunter, I., "Rol y poderes del juez civil: una mirada desde la eficiencia del proceso" en Revista de Derecho Universidad Católica del Norte, año 18, No 2, 2011, pp. 73-101.

López, J., Análisis económico del Derecho, Tecnos, Madrid, 1987.

Marinoni, L., Pérez Ragone, A. y Núñez, R., Fundamentos del proceso civil. Hacia una teoría de la adjudicación, Abeledo Perrot, Legalpublishing, Santiago, 2010.

Moreno, V. y Cortés, V., Introducción al Derecho Procesal, Tirant lo Blanch, Valencia, 2004.

Moreso, J. y Vilajosana, J., Introducción a la teoría del Derecho, Marcial Pons, Madrid, 2004.

Nasi, A., Disposizione del diritto e azione dispositiva, Contributio allo Studio del principio dispositivo nel processo civile di cognizione, Giuffrè Editore, Milán, 1965.

Normand, J., "I poteri del giudice e delle parti quanto al fondamento delle pretensa controverse" en Rivista di Diritto Processuale, Vol. XLIII, pp. 722-750.

Ormazábal, G., Iura novit curia. La vinculación del juez a la calificación jurídica de la demanda, Marcial Pons, Madrid, 2007.

Ortells, M., "Principio acusatorio, poderes oficiales del juzgador y principio de contradicción. Una crítica de cambio jurisprudencial sobre corrección entre acusación y sentencia” en Justicia 91, N4, 1991, pp. 775-798.

Ortells, M., Derecho Procesal Civil, Thomson Aranzadi, 2008.

Pastor, S., “¿Penuria de medios? Un análisis empírico de los costos públicos y privados visibles y ocultos de la justicia”, en La justicia procesal, Consejo General del Poder Judicial, VI, Madrid, 2008, pp. 347 a 434.

PAstor, S., "El coste de la justicia: datos y un poco de análisis" en El coste de la justicia, Consejo General del Poder Judicial, Madrid, 2002, pp. 31-72.

Picardi, N., "Il principio del contraddittorio", en Rivista di Diritto Processuale, Vol. LIII, No 3 , 1998, pp. 672-681.

Picó i Junoy, J., El derecho a la prueba en el proceso civil, Bosch Editor, Barcelona, 1996. 
RICCI, G., “'Individuazione’ o ‘sostanziazione’ nella reforma del proceso civile”, en Rivista Trimestrale de Diritto e Procedura Civile, año XLIX, 1995, pp. 1227-1251.

Romero, A., "La congruencia de la sentencia" en Revista Chilena de Derecho, Vol. XXV, No 2 , 1998, pp. 447-451.

Romero, A., La cosa juzgada en el proceso civil. Doctrina y jurisprudencia, Editorial Jurídica de Chile, Santiago, 2002.

TAPiA, I., El objeto del proceso. Alegaciones. Sentencia. Cosa juzgada, Editorial La Ley, Madrid, 2000.

TARuffo, M., La prueba de los hechos, Editorial Trotta, Madrid, 2009.

Taruffo, M., Páginas sobre la justicia civil, Marcial Pons, Madrid, 2009.

Tarzia, G., "Poteri delle parti e poteri del giudice", en Problemi del processo civile di cognizione, Cedam, Padova, 1989.

Trocker, N., Processo civile e costituzione. Problemi di diritto tedesco e italiano. Giuffrè Editore, Milán, 1974.

Verde, G., Profili del proceso civile. Parte generale, $2^{a}$ edición, Jovene Editore, Nápoles, 1988.

YllesCA, R., "El principio iura novit curia y la posición del abogado en el proceso" en La Ley, $\mathrm{N}^{\circ} 3,1994$, pp. 827-843. 
